
Roberto Salvador Scaringella, engenheiro civil
(Escola Politécnica de São Paulo); atualmente
é diretor do Departamento de Operação do
Sistema Viário - DSV - e presidente da
Companhia de Engenharia de Tráfego - CET -
da prefeitura do município de São Paulo.

Roberto Salvador Scaringella

\title{
Uma revisão no gerenciamento de mobilidade urbana
}

A atuação do poder público no gerenciamento das cidades grandes ou pequenas tem sido sempre pautada pela supervalorização das grandes obras, grandes investimentos e a pouca importância dada aos serviços, à operaçãa propriamente dita das cidades.

A própria universidade que prepara o técnico se preocupa em formar um construtor de coisas novas e grandes, e não um operador dedicado a dar mais eficiência à operação da cidade como um todo.

Não se tem consciência do primado da operação do existente sobre a nova grande obra - esta, cada vez mais, carente de recursos. O tratamento da mobilidade urbana não fugiu a essa versão.

Buscam-se propor soluções de aplicação do capital intensivo como se nelas se esgotassem as possibilidades de tratamento do problema. Ainda tem-se a estreita visão de subestimar soluções de baixo custo, os tratamentos em nível operacional, como se as cidades só necessitassem ser construídas e nunca operadas, para não se falar na operação com eficiência.

Pouca gente mesmo, técnica ou não, que de alguma forma trata com o urbano, defende o primado da operação sobre a construção, o investimento, a grande obra.

Nas cidades brasileiras de todos os tamanhos, não se explora a grande potencialidade do aumento de eficiência (dos vários servicos urbanos) com poucos recursos financeiros e recursos humanos qualificados.

A estrutura burocrática, técnica, de mentali- dade, a própria universidade, as repartições públicas, as empreiteiras, todas estão estruturadas para a época de euforia econômica (para não se dizer milagre). Tudo está voltado para a hipótese - cada vez mais distante - de grandes obras, grandes investimentos, grandes cirurgias urbanas, buscando propostas de soluções do ponto de vista de sua materialização. Não há, porém, a busca de grandes propostas que mobilizem o existente e o possivel. Verdade é que o serviço não aparece: é de difícil materialização; aparece apenas quando falha.

O binômio transporte-trânsito sofreu na década de 1970 uma reversão de expectativa muito grande. A crise energética, as cidades sem dinheiro, fomentaram por demais a busca da simplificação das clássicas soluções que Los Angeles, Nova York, Tóquio ou Paris procuravam há décadas, ou o mesmo que as cidades brasileiras se propunham.

Alguns estudos de tráfego urbano, na virada dos anos 1960 para 70, indicavam cirurgias urbanas de tal vulto que o próprio conceito de cidade estava comprometido, dadas as necessidades para se testar a viabilidade de cidades calcadas no transporte individual.

A crise da década de 1970, que do ponto de vista de trânsito e transporte foi só parcialmente assumida, trouxe o benefício de forçar os técnicos a buscar soluções mais simples, de menor custo e de curto prazo de execução.

Nesse ajustamento 'ao real', descobriram-se a operação das cidades, os serviços, o custeio, as pequenas obras, as medidas de regulamento, a importância da comunicação social ligada aos serviços urbanos. 
Talvez o início dos anos 80 venha indicar a conscientização, a descoberta não apenas de uma elite pensante, mas de 'algo' além do que as indiscutivelmente importantes e necessárias grandes obras, cada vez menos viáveis à luz dos orçamentos de investimentos dos três niveis de governo.

Um fator decisivo nessa descoberta coletiva é o conteúdo das reivindicações populares dos últimos tempos. A classe política, os técnicos, a burocracia oficial, devem dar-se conta de que reclamase mais, em termos urbanos, por serviços do que por obras; por pequenas coisas do que por grandes cirurgias urbanas; talvez mais da manutenção inadequada e precária do serviço existente do que por um novo serviço.

O aumento de eficiência dos serviços existentes nas grandes cidades, talvez em certos casos, tivesse mais impacto social do que a criação de novos servicos.

Geralmente a implantação de um serviço se torna mais fácil que a recuperação de um já existente. Este último necessita de um grande esforço de melhoria de recursos humanos (talvez nosso maior desafio): a capacitação em niveis aceitáveis e adequados.

Nesse quadro de economia de escassez - infelizmente ainda não assumido - para observar as soluções de muitos problemas de transporte e trânsito, como se poderia prever a crise de mobilidade urbana da virada do século?

Das infinitas interdependências dos fatores, das influências mútuas com os demais fatores - onde as propostas de soluções coordenadas raramente se colocam de forma menos técnica e mais operacional - poderemos chamar algumas ao debate.

\section{O tráfego e o uso do solo}

Um dos problemas mais sérios enfrentados na operação do trânsito das grandes cidades brasileiras origina-se no crescimento e adensamento urbanos, que vem se desenvolvendo de forma defasada da expansão dos sistemas viários e de transportes existentes. Além disso, a instalação de determinadas atividades em áreas que não dispõem de vias de acesso capazes de absorver o volume de veículos por elas atraídos, acarreta reflexos negativos na operação do tráfego. É em conseqüência dessa situação que as cidades passam a enfrentar constantes congestionamentos em pontos nevrálgicos; má acessibilidade aos pontos de interesse da população; circulação e estacionamento em áreas residenciais; desobediência à sinalização e constantes riscos de acidentes de trânsito.

A causa desses problemas está, em grande parte, nas legislações municipais vigentes, que não contam com as necessárias restrições suscetiveis de evitar o surgimento de novos pontos geradores de tráfego e de problemas para a comunidade.

Nas grandes cidades brasileiras, de uma maneira geral, a legislação reguladora do crescimento urbano é omissa, no que diz respeito aos problemas advindos do tráfego, e é desatualizada quanto à existência de vagas de estacionamento das novas construções. Essa legislação não conta também com as devidas restrições relativas à concentração, em determinadas áreas, de grandes e pequenos pólos geradores de tráfego (comércio, indústria, lazer etc.) que atraem um volume de veículos que, na maioria dos casos, não tem condições de ser absorvido pelo sistema viário existente, sem falar que a demanda de vagas de estacionamento não é suprida no interior dessas edificações.

Na cidade de São Paulo, tais problemas foram detectados por um estudo que vem sendo realizado pela Companhia de Engenharia de Tráfego (CET) e que propõe as necessárias alterações. Nesse trabalho, uma das críticas levantadas à legislação atual diz respeito à inexistência de restrições específicas quanto à localização de grandes pólos geradores de tráfego em vias de baixa capacidade, ou já saturadas, ou de micropólos em vias de tráfego de passagem.

Foi ainda o estudo sobre os pólos geradores que evidenciou a desatualização dos índices que relacionam as características de edificação com os veículos. Em primeiro lugar, há uma insuficiência de vagas destinadas a estacionamento, pois a exigência atual de uma vaga para cada $50 \mathrm{~m}^{2}$ de construção equivale, no caso de cursinhos, a cerca de uma vaga para cada grupo de 40 alunos, ou no caso dos restaurantes, a uma vaga para 25 fregueses - o que é notoriamente insuficiente. Um segundo ponto é a insuficiência de áreas para carga e descarga, com pátios subdimensionados, provocando filas de caminhões em ruas residenciais. Finalmente, o estudo constata a insuficiência de áreas para embarque e desembarque, o que causa embarque em fila dupla, com insegurança para o pedestre ou filas de táxis ocupando uma faixa de trânsito da via.

Afora esses aspectos levantados no que diz respeito ao zoneamento da cidade, o estudo realizado pela CET analisou o Código de edificações que, muitas vezes, não apresenta de modo adequado critérios e dados para o dimensionamento das áreas destinadas aos veículos, ou seja, espaço insuficiente para manobras além de dimensionamento e disposições de vagas incorretos, o que acarreta perda na capacidade de estacionamento.

Constata-se, ainda, uma inadequação dos cri- 
térios de dimensionamento dos acessos e área de acumulação de veículos, o que se reflete no tráfego de passagem, dificultando manobras e provocando acidentes.

Por outro lado, de uma forma geral, a legislação não atende às condições mínimas de segurança do pedestre, permitindo, por exemplo, saída de multidão de pessoas numa avenida de grande movimento e não evitando os problemas causados pela travessia de pedestres atraídos pela implantação de um pólo gerador de tráfego.

Essas questões, registradas em São Paulo mas também comuns a outras cidades de grande porte no país - apresentam uma tendência a avolumar-se cada vez mais. Em São Paulo, exemplificando, pode-se observar a elevada disparidade entre o crescimento ocorrido no período 1967-1980, quando a frota de automóveis aumentou cerca de $350 \%$, contra $80 \%$ da população e somente $25 \%$ dos sistema viário. Apesar do aumento da frota ter declinado nos últimos anos, sua taxa de crescimento é ainda muito superior às taxas de ampliação do sistema viário.

É preciso, portanto, que as autoridades das grandes cidades brasileiras estejam atentas para essa problemática, a fim de evitar, para o futuro, os sérios problemas causados ao tráfego pela ausência de legislação específica ou omissões na legislação existente. Convém atuar diretamente sobre os instrumentos legais que regulam o uso do solo e as características físicas de projeto dos empreendimentos. O que se propõe é um conjunto de modificações nesses instrumentos, tornando viável um controle maior sobre as edificações, que, por sua própria natureza, podem causar transtornos ao tráfego em geral.

\section{Transporte coletivo}

Talvez o maior desafio do transporte coletivo seja o problema tarifário, cuja abordagem no Brasil ainda não mereceu a devida atenção, dado o aprofundamento e o realismo que o problema impõe. Junto a esse problema está a ampliação de oferta de lugares que colide frontalmente com a escassez de recursos para os investimentos.

As cidades serão inviáveis se desprovidas de um forte sistema de transporte coletivo, pois, mesmo se servindo de combustível de baixo custo, as cidades são inviáveis quando se calcam as soluções no transporte individual.

A difícil, mas inevitável, racionalização dos sistemas atuais deverá ter papel de grande relevância, se executada a curto prazo. O potencial de benefício desse tipo de tratamento é surpreendentemente grande. Por exemplo, no município de São Pau- lo, medidas parciais de racionalização da circulação chegaram a acrescentàr $90 \%$ na velocidade convencional dos corredores de transportes quase saturados.

Outras medidas são igualmente importantes: o treinamento de motorista de ônibus, a racionalização de itinerários das frotas, a política de operação e manutenção adequadas das mesmas. Essas providências, associadas a outras que visam ao conforto do usuário - tais como abrigos montados adequadamente (uma raridade no Brasil todo), informação ao usuário, regularidade de horários - constituem-se num conjunto das pequenas coisas fundamentais tão esquecidas entre nós.

\section{Comportamento}

A passagem de um modelo de desenvolvimento urbano calcado na supervalorização das grandes obras para um outro modelo que buscasse a racionalização do existente nas cidades, a ênfase em construções de baixo custo, ou ainda voltado para o aspecto operacional, requer uma mudança de mentalidade, que já começa a aparecer, mas que ainda precisa ser fortemente estimulada.

Daqui para o futuro, o que vier a ser investido na melhoria do comportamento das pessoas frente à vida urbana terá importância vital para nossas cidades. A comunidade quer ser informada e quer participar.

As pessoas estão hoje em dia isoladas, desinformadas a respeito do que é a cidade ou do que ela pode ser. Não sabem às vezes, sequer, qual seria um padrão adequado de comportamento para sobreviver na cidade.

Atualmente, o poder público não informa nem mesmo para promover adequadamente o seu trabaIho, ou mesmo divulgá-lo. A linguagem usada pelo poder público através da mídia de TV, rádio ou jornal, por exemplo, ainda não é a indicada para realmente atingir a população, a fim de torná-la participante e consciente da necessidade de uma mudanca de comportamento frente aos problemas do diaa-dia de uma cidade. É necessário encontrar-se uma linguagem adequada para transmitir as informações precisas e as orientações sobre tudo aquilo que acontece nas cidades, concomitantemente às mensagens comunicadas às pessoas sobre o comportamento indicado para essas situações. Esse trabalho de informação, esclarecimento e orientação da população, induzindo-a a participar dos problemas e das soluções, parece ser o caminho educacional mais adequado para atingir-se os desejados padrões de civilidade da população para com sua cidade.

No caso dos acidentes de trânsito, a melhoria do comportamento do motorista e do pedestre 
apresenta-se como um dos principais fatores para que, no futuro, as cidades brasileiras possam ter índices bem menores do que os atuais, que colocam o Brasil na indesejável e incômoda situação de recordista.

Contudo, para que possamos alcançar tais objetivos, é indispensável que a sociedade esteja empenhada como um todo. Os meios de divulgação devem dar a sua parcela de contribuição para difundir as informações e orientações adequadas à formação (no caso das crianças) e à mudança de comportamento (no caso de adultos).

O meio mais apropriado para se atingir a miIhões de pessoas é, realmente, a televisão. Mas o poder público municipal não tem condições orçamentárias para manter campanhas, que tem seu custo altíssimo. Seria da mais alta valia e de um alcance social dos maiores se os diversos canais de televisão dessem a sua colaboração: alguns minutos diários, distribuídos em espaço de 10 a 30 segundos. Com esses espaços e com a linguagem adequada, seria possível sensibilizar grande parte da população, conscientizando-a da necessidade de comportamentos convenientes não só frente ao trânsito, mas frente à sua cidade e respectivos problemas.

\section{A municipalidade do trânsito}

Outro fator preponderante para o melhor equacionamento da mobilidade urbana, no futuro, é sem dúvida aquele que trata da municipalização do trânsito, ou seja, destinar à administração municipal a responsabilidade pela fiscalização, educação e, principalmente, pela operação do tráfego na área de sua competência.

Os municípios têm especial interesse pelos problemas de tráfego urbano porque estes Ihes causam impacto direto na segurança dos deslocamentós de veículos e pedestres, na eficiência dos transportes públicos, com decisiva influência no uso do solo urbano e nas condições de abastecimento da população.

É importante ressaltar que as soluções desses problemas dependem de particularidades de cada local, como volume de tráfego, circulação, topografia, sazonalidade de fenômenos, hábitos da população etc. O conhecimento satisfatório de todos esses aspectos - vital para as soluções adequadas será somente obtido mediante contato permanente dos técnicos especializados com os problemas em pauta.

Outro aspecto relevante é a necessidade da gestão integrada dos serviços de engenharia, educação e fiscalização do tráfego urbano, devendo este último englobar a aplicação das penalidades decor- rentes das infrações de trânsito. Nesse modelo, já funciona o Departamento de Operação do Sistema Viário (DSV) do município de São Paulo, que assumiu essas atribuições em 1973, mediante convênio celebrado entre essa municipalidade e o governo do Estado de São Paulo.

Os resultados dessa experiência pioneira têm । sido dos mais auspiciosos. Novas técnicas e sistemas foram empregados, alguns criados e outros adaptados, sempre direcionados na melhoria do trânsito da capital, porém com reflexos no desenvolvimento da engenharia de trânsito nacional.

Convém estender essa medida a outros municipios brasileiros, que atendam a algumas premissas. Já foi sugerido que sejam considerados para adotar tal solucão os municípios com população superior a 200 mil habitantes, ou que tenham uma frota registrada acima de 30 mil veículos automotores, ou cuja arrecadação tributária geral anual seja superior a um milhão de vezes o valor da ORTN, ou ainda, que atendam a outros critérios que possam ser determinados pelo Conselho Nacional de Trânsito CONTRAN. A prefeitura do município de São Paulo já encaminhou sugestão nesse sentido ao Ministério da Justiça para a devida análise.

Para que se tenha idéia do alcance de uma decisão como essa, basta mencionar que são 59 as cidades brasileiras com população acima de 200 mil habitantes ou com frota acima de 30 mil veículos registrados. Ver lista apresentada no final deste artigo.

\section{A segurança de trânsito}

O maior problema do trânsito nas grandes cidades brasileiras, atualmente, é sem dúvida o da segurança. Os índices de acidentes com seus feridos e seus mortos ainda são muito elevados e trazem grandes prejuízos materiais à sociedade e principalmente inúmeras vítimas e perdas humanas.

Em São Paulo, a prefeitura, por meio da CET e do DSV, tem mostrado preocupação constante a respeito dessa situação e vem implantando uma série de medidas a nível de engenharia, fiscalização e educação. Mas, ao mesmo tempo, tem-se a consciência de que esse esforço mostra-se impotente para sanar as principais causas desse problema, que não existe apenas em São Paulo, mas em todo o Brasil, com índices ainda mais assustadores. O número de pessoas que, atualmente, morrem no país em acidentes de trânsito chega à casa dos 20 mil, sem falar nas centenas de milhares de feridos e nos vultosos danos materiais. Em termos nacionais, os acidentes provocam um custo superior a 30 milhões de cruzeiros anuais, representados pela perda de produção, custo de atendimento médico-hospitalar, indenizações, aposentadorias etc. 
Os técnicos da Companhia de Engenharia de Tráfego que, há alguns anos, vêm-se dedicando ao estudo do problema do acidente, pesquisaram as ações realizadas em países com tradição automobilistica maior que a nossa. Chegaram a algumas conclusões importantes e passíveis de serem colocadas em prática no Brasil.

Os exemplos mais significativos e de sucesso comprovado nos chegam da França e do Japão, onde os índices de acidentes de trânsito apresentaram uma redução bastante considerável. Nesses dois países, adotou-se a decisão de constituir um organismo em nível nacional, com a única preocupação de tratar da segurança viária. Esses órgãos contam com a participação direta de todos os ministérios envolvidos no problema. Além disso, também nos níveis estadual e municipal foram criadas comissões com o mesmo objetivo para que o esforço concentrado das autoridades obtivesse resultados positivos quanto à redução dos acidentes e das vítimas no trânsito. Na França o Conselho Interministerial da Segurança Viária e no Japão o Comitê Central para Medidas de Segurança de Trânsito vêm tomando resoluções nas áreas de legislação, engenharia, fiscalização, educação e em todos os campos ligados ao trânsito, a fim de garantir uma mudança de comportamento do motorista e pedestres, já que a imperícia e a imprudência são os principais responsáveis pelos acidentes.

No Brasil, onde os números chegam a ser alarmantes, entendemos que chegou o momento de incluir a 'segurança do trânsito' na relação dos problemas brasileiros que merecem uma ação coordenada que reúna os organismos governamentais ligados ao problema.

À semelhança do que aconteceu na França e no Japão, deveria ser criado o que poderia ser chamado de Conselho Interministerial da Segurança do Trânsito, do qual participariam os ministérios direta e indiretamente ligados à matéria. Entre outros, estariam os ministérios dos Transportes, dâ Justiça, da Educação e Cultura, do Exército, da Indústria e Comércio, da Saúde e do Planejamento. Dessa forma, seria possível conseguir a polarização de todos esses órgãos, facilitando a definição, coordenação e implantação das principais medidas a serem adotadas, sem falar na necessária destinação de recursos humanos e materiais compatíveis com a envergadura das referidas ações.

Por meio de um programa plurianual para segurança do trânsito, esse Conselho ditaria as normas e ações necessárias e recomendadas para todo o país. O trabalho seria complementado nos níveis estadual e municipal, onde criar-se-iam comissões específicas de segurança de trânsito.

\section{Legislação}

Além dos aspectos abordados, entendemos que o da legisção está entre os mais importantes, já que todos os demais dependerão de sua evolução para que, na virada do século, esteja viabilizado um novo modelo de mobilidade urbana mais adequado à realidade do país.

Urge uma agilização, dentro do esquema legal existente, dos processos judiciais relativos a acidentes de trânsito, processos esses que hoje em dia têm seguimento muito lento, trazendo como conseqüência a impunidade dos responsáveis pelos acidentes e outras infrações. As decisões mais rápidas teriam um caráter educativo dos maiores, com resultados positivos no esforço de redução de acidentes de trânsito - como já aconteceu em outros países.

Por outro lado, é extremamente relevante proceder a uma revisão no Código nacional de trânsito, a fim de que esteja perfeitamente compatibilizado com a realidade e com as exigências das cidades brasileiras. É necessário que haja um rigor maior na aplicação e no cumprimento das penalidades previstas para as infrações de trânsito.

Evidentemente, também há mister de levar a efeito uma revisão e adaptação do Código civil e do Código penal brasileiros, com o objetivo de tratar os acidentes de trânsito com a atenção que lhes é devida, já que milhares de vidas se perdem anualmente nas cidades e estradas brasileiras.

Nota: cidades brasileiras com populacão superior a 200 mil habitantes ou com frota acima de 30 mil veículos registrados: São Pau10: São Paulo, Campinas, Santo André, Guarulhos, Osasco, São Bernardo, Santos, Ribeirão Preto, São José dos Campos, Sorocaba, Jundiai, Diadema, Piracicaba, Mauá, Mogi das Cruzes, São Caetano do Sul, São José do Rio Preto, Bauru; Rio de Janeiro: Rio de Janeiro, Nova Iguaçu, São Gonçalo, Duque de Caxias, Niterói, Campos, Petrópolis; Minas Gerais: Belo Horizonte, Juiz de Fora, Contagem, Urberlândia; Bahia: Salvador, Feira de Santana; Ceará: Forataleza; Pernambuco: Recife, Jaboatão, Olinda; Distrito Federal: Brasília; Rio Grande do Sul: Porto Alegre, Pelotas, Caxias do Sul, Canoas; Paraná: Curitiba, Londrina: Pará: Belém; Goiás: Goiânia; Amazonas: Manaus; Maranhão: São Luís, Imperatriz; Rio Grande do Norte: Natal; Alagoas: Maceió; Piauí: Teresina; Paraíba: João Pessoa, Campina Grande; Sergipe: Aracaju; Mato Grosso do Sul: Campo Grande; Santa Catarina: Florianópolis, Joinville; Mato Grosso: Cuiabá; Espírito Santo: Vitória, Vila Velha. 
